www.jmscr.igmpublication.org

Impact Factor (SJIF): 6.379

Index Copernicus Value: 71.58

ISSN (e)-2347-176x ISSN (p) 2455-0450

crossref DOI: https://dx.doi.org/10.18535/jmscr/v6i5.01

Journal Of Medical Science And Clinical Research

\title{
Diode Laser Surgery of Multiple Traumatic Fibromas of the Buccal Mucosa in Patient Taking Oral Anticoagulant: Conventional and Confocal Laser Scanning Microscopical Examination
}

\author{
Authors \\ Luisa Limongelli, DDS, Angela Tempesta, DDS, Saverio Capodiferro, DDS \\ Department of Interdisciplinary Medicine, “Aldo Moro" University of Bari, Piazza G. Cesare 11, 70124, \\ BARI, ITALY \\ Corresponding Author \\ Saverio Capodiferro, DDS \\ Department of Interdisciplinary Medicine, Complex Operating Unit of Odontostomatology, "Aldo Moro" \\ University of Bari, Piazza G. Cesare 11, 70124, BARI, ITALY \\ Tel: +39 0803483768; Email: capodiferro.saverio@gmail.com
}

\begin{abstract}
To report on a case of multiple traumatic fibromas of the buccal mucosa surgically removed by diode laser (wavelength $980 \mathrm{~nm}$, laser set to 1,5 Watt in continuous wave, fibre of 300micron in diameter) in a patient receiving oral anticoagulants, in order not to suspend or modify the set therapy and performed a safe surgery with complete control of the intra-operative bleeding, and nonetheless making stiches unnecessary. Histological examination of the specimens and confocal laser scanning microscopical examination of the deep margins of excision was performed to evaluate the interaction among diode laser and biological tissues.

Keywords: Traumatic fibroma, benign neoplasm, oral mucosa, diode laser surgery, oral anticoagulant, confocal laser scanning microscopy.
\end{abstract}

\section{Introduction}

The occurrence of traumatic fibroma (TF) in the oral mucosa is very high and the conservative surgery with complete excision of the lesion is usually the proper therapy unless irritation or traumatic factors are not removed ${ }^{[1,2]}$.

Nevertheless, such occurrence can become a challenge for the surgeon when patient suffer anticoagulant therapy and/or is affected by systemic diseases that can delay the blood clotting time. The diode laser is a medical device useful in such cases since it has properties that allow to cut and coagulate at the same time without creating alterations of the surgical specimens for the final histological diagnosis ${ }^{[3,4,5]}$.

\section{Case Report}

A 54 year-old Caucasian male was referred for two proliferating lesions of the left cheek mucosa. The intraoral examination revealed two distinct formations of several months duration (Fig. 1), painless, sessile, round and covered by notulcerated mucosa even if related to the biting trauma. The patient was in therapy with 
anticoagulant (warfarin) to prevent complication related to the atrial fibrillation he suffered. With the suspicious of reactive lesions, surgical excision was suggested by using a diode laser $(980 \mathrm{~nm})$ in order not to suspend or modify the set anticoagulant therapy. Under local anaesthesia, both lesions were surgically removed with margins adequate to the clinical diagnosis, by using a fibre of 300micron in diameter and with the diode laser sets to $1,5 \mathrm{~W}$ att in continuous wave. This is a Watt value output higher than conventional 0,6 - 0,8 Watt usually necessary to perform such kind of interventions, but useful in such patient taking oral anticoagulant to avoid any possible intraoperative bleeding. Nevertheless, no stiches were necessary. The histological examinations of the surgical specimens leads to the diagnosis of multiple traumatic fibromas (Fig. 2 ). The deep margin showed signs related to the thermal cut of the diode laser used with a high output energy (Fig. 3 a) and, although unnecessary for the diagnosis, were investigated by confocal laser scanning microscopyat high magnification to assess the quality of laser-tissue interaction (Fig. 3 $\mathrm{b}, \mathrm{c}, \mathrm{d})$. The post-operative course was uneventful and the complete healing for second intention of the cheek mucosa observable after 14 days (Fig. 4).

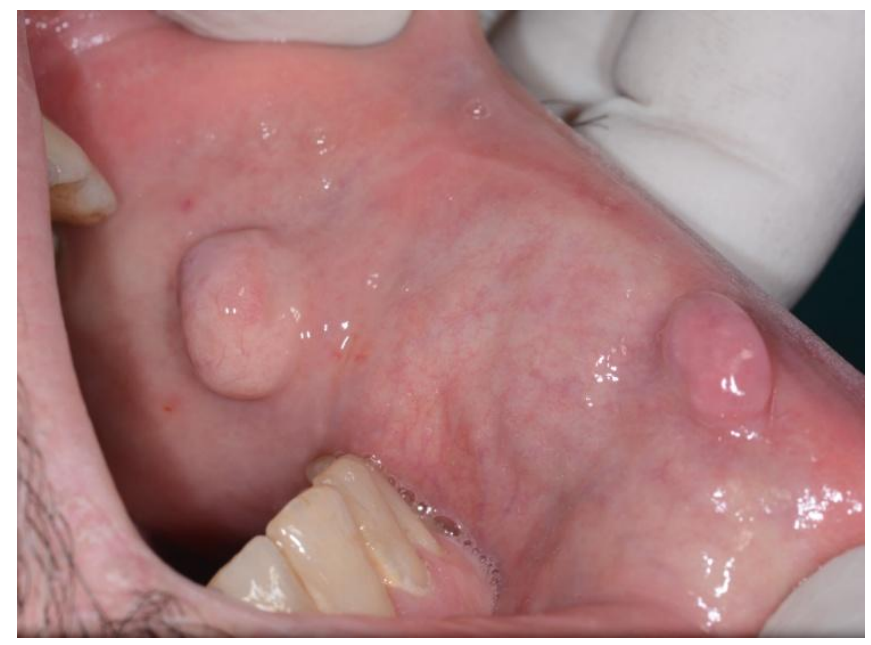

Figure 1.The classic appearance of $\mathrm{TF}$ as a sessile and round formation, covered by not-ulcerated mucosa.

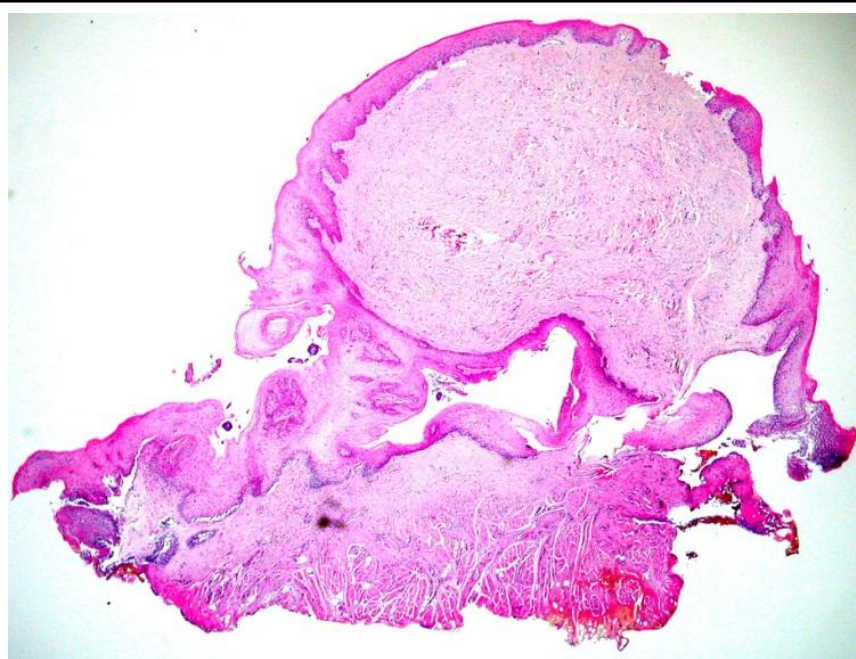

Figure 2. Histological examination showing an uncapsulated nodular mass of connective tissue covered by un-ulcerated stratified squamous epithelium; collagen bundles show a prominent radiating fashion (H\&E stain, original magnification $\mathrm{x} 2$ ).
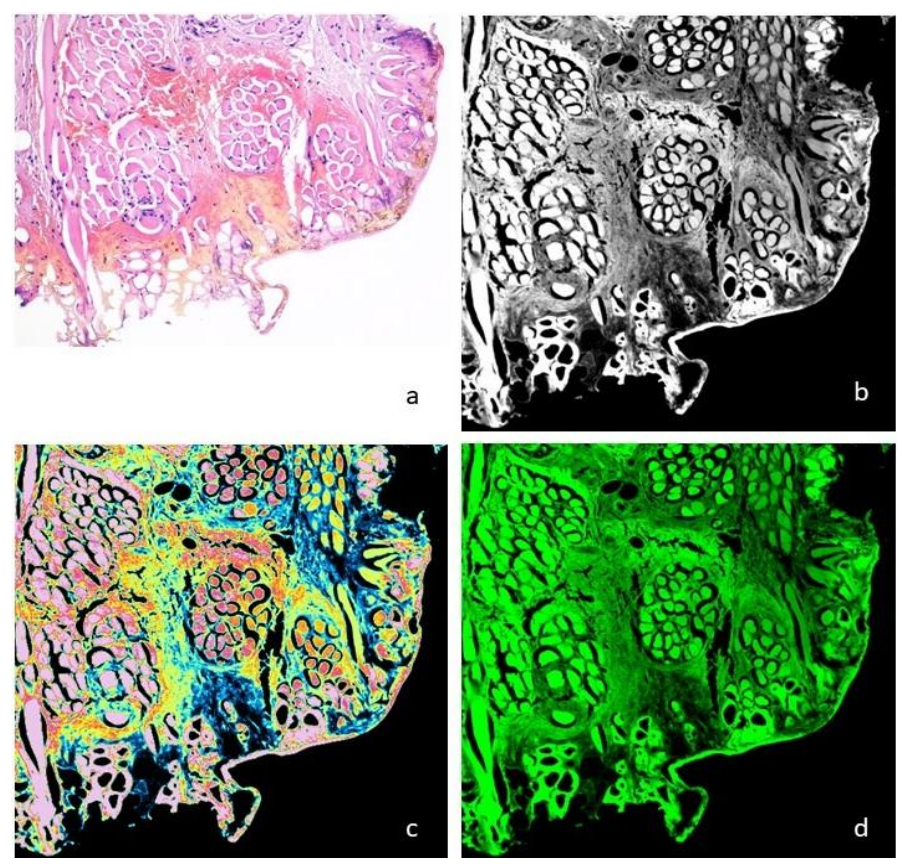

Figure 3 (a, b, c, d). Thermal cut effects of diode laser detectable on histological examination are essentially related to a high output energy (a, H\&E, x 20); nevertheless, it does not create overall morphological-structural alterations of the samples that can create difficulties for the diagnosis, as confirmed by the confocal laser microscopy scans which highlight the rather normal appearance of muscle cells although close to the laser cut margin (b, c, d). 


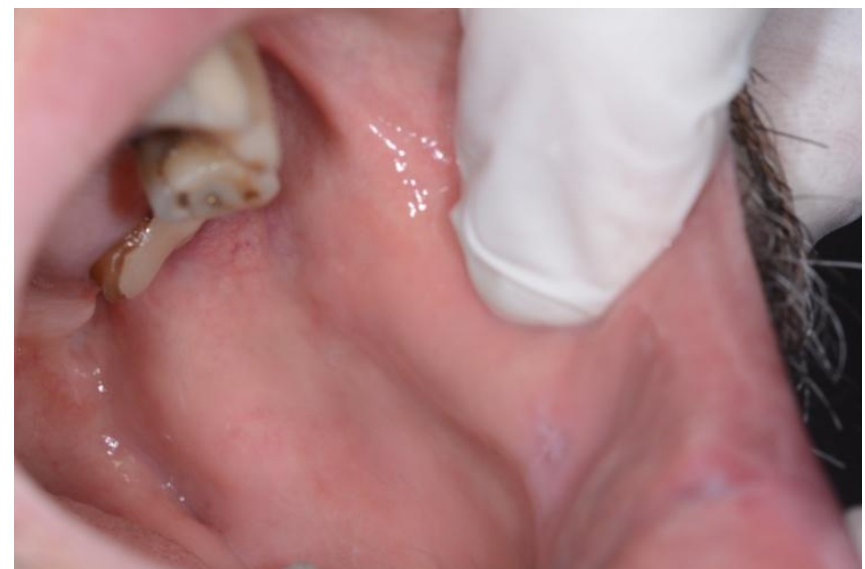

Figure 4. The complete healing by second intention of the cheek mucosa observable after 14 days.

\section{Discussion}

Fibroma of the oral mucosa, also called irritation or traumatic fibroma (TF), is the most common oral tumour-like growing lesion essentially related to the focal fibrous hyperplasia due to trauma or local irritation ${ }^{[1,3]}$. TFcan occur anywhere in the mouth but the most common location is the buccal mucosa along the bite line, surely for the frequent trauma relating to the cheek biting; less frequent is the occurrence in labial mucosa, tongue and gingiva $^{[1,2]}$. Nevertheless, clinically appearance of $\mathrm{TF}$ is usually a painless, sessile, round or ovoid mass, lighter in colour than surrounding mucosa due to a reduced vascularity, usually covered by not-ulcerated mucosa. Conservative surgery is usually the best treatment for such benign lesions, and recurrences occur also when primary irritation or traumatic factors are not removed ${ }^{[1,2,3]}$. However, conventional surgery can become difficult in patient affect by systemic diseases with following bleeding disorders or more frequently by medication (anticoagulants) that can interfere with the blood clotting. The diode laser surgery provides several advantages as less bleeding, a shorter procedure time, unnecessary stiches, better healing, less complications, no ultra-structural alterations of the surgical specimen for the following histological examination ${ }^{[3,4,5]}$; the latter were confirmed by confocal laser scanning microscopical examination performed in the reported case (Fig. 3 a, b, c, d).

\section{Conclusions}

We conclude that diode laser surgery for benign and/or traumatic lesions of the oral mucosa is the easier and rapid surgical technique, promoting several advantages also in patients with delayed blood clotting time due to drugs therapy or systemic diseases. Nevertheless, like for conventional surgery, a surgical excision with wide lateral and deep margins is advised also for laser surgery, to obtain a surgical specimen free of disease on the histological examination that remains mandatory for the final diagnosis of all proliferating lesions of the oral mucosa. In addition, the thermal cut effects of diode laser detectable on histological examination do not create overall morphological-structural alterations of the samples that can create difficulties for the differential diagnosis above all in doubtful cases.

\section{Conflict Of Interest}

Author declare no conflict of interest.

\section{References}

1. Sangle VA, Pooja VK, Holani A, Shah N, Chaudhary M, Khanapure S. Reactive hyperplastic lesions of the oral cavity: A retrospective survey study and literature review. Indian J Dent Res. 2018;29(1):6166.doi: 10.4103/ijdr.IJDR_599_16.

2. Perales-Garza RV, Sierra-Garcia GD, Nájera RI, Perales-Perez ÁV. Management of Traumatic Fibroma in a Patient with Cerebral Palsy Using 810nm Diode Laser. JClin Diagn Res. 2017;11(2):ZD01-ZD02. doi: 10.7860/JCDR/2017/20084.9125.

3. Ortega-Concepción D, Cano-Durán JA, Peña-Cardelles JF, Paredes-Rodríguez VM, González-Serrano J, López-Quiles J. The application of diode laser in thetreatment of oral soft tissues lesions. A literature review. J ClinExp Dent.2017; 9(7):e925-e928.doi: 10.4317/jced.53795.

4. Capodiferro S, Maiorano E, Loiudice AM, Scarpelli F, Favia G. Oral laser surgical pathology: a preliminary study on the 
clinical advantages of diode laserand on the histopathological features of specimens evaluated by conventional and confocal laser scanning microscopy. Minerva Stomatol. 2008;57(1-2):1-6,6-7.

5. Capodiferro S, Maiorano E, Scarpelli F, Favia G. Fibrolipoma of the liptreated by diode laser surgery: a case report. J Med Case Rep. 2008;12;2:301. doi: 10.1186/1752-1947-2-301. 